\title{
Joint Healthcare Professional and Patient Development of Communication Tools to Improve the Standard of MS Care
}

\author{
Celia Oreja-Guevara · Stanca Potra · Birgit Bauer · Diego Centonze · Maria-Paz Giambastiani • \\ Gavin Giovannoni · Jürg Kesselring · Dawn Langdon · Sarah A. Morrow · Jocelyne Nouvet-Gire • \\ Maija Pontaga · Peter Rieckmann · Sven Schippling · Nektaria Alexandri · Jane Shanahan • \\ Heidi Thompson · Pieter Van Galen · Patrick Vermersch · David Yeandle
}

Received: July 3, 2019 / Published online: September 5, 2019

(C) The Author(s) 2019

\section{ABSTRACT}

Introduction: Effective communication between patients and healthcare professionals (HCPs) is important to enhance outcomes in multiple sclerosis (MS). However, in practice, patients often report a disconnect in communication. Communication tools to aid patient-HCP communication have a long history of use in many chronic conditions. For example, symptom diaries have been

Enhanced Digital Features To view enhanced digital features for this article go to https://doi.org/10.6084/ m9.figshare.9633170.

Electronic Supplementary Material The online version of this article (https://doi.org/10.1007/s12325019-01071-9) contains supplementary material, which is available to authorized users.

C. Oreja-Guevara $(\bowtie)$

Servicio de Neurología, Hospital Clínico San Carlos, IdISSC, Departamento de Medicina, Universidad

Complutense, Madrid, Spain

e-mail: orejacbn@gmail.com

\section{S. Potra}

Member of the MS in the 21st Century Steering

Group, Bucharest, Romania

B. Bauer

Member of the MS in the 21st Century Steering

Group, Berlin, Germany

D. Centonze

Unit of Neurology, IRCCS Neuromed, Pozzilli, IS, Italy shown to enhance outcomes in cancer, headache and sleep disorder management. MS in the 21st Century, a Steering Group of HCP specialists and patients with MS (PwMS), has created two communication tools designed for use by both patients and their HCPs.

Methods: The Steering Group first identified prominent issues in patient-HCP communication through group discussions and survey data. Following this, a series of workshops led to the development of two communication tools as potential solutions to these identified issues in communication.

Results: The two most prominent issues identified were HCP time constraints during appointments and the misalignment of patient and HCP priorities-the communication tools developed through the workshops were created to address these. The "myMS priorities" tool [see

M.-P. Giambastiani

Member of the MS in the 21st Century Steering

Group, Bilbao, Spain

G. Giovannoni

Blizard Institute, Barts and the London School of

Medicine and Dentistry, London, UK

J. Kesselring

Kliniken Valens, Valens, Switzerland

D. Langdon

Royal Holloway, University of London, London, UK

S. A. Morrow

Western University, London, ON, Canada 
supplementary materials] is designed to maximize the use of consultation time while the "myMS commitments" tool [see supplementary materials] aims to improve patient-HCP shared decision-making.

Conclusions: The MS in the 21st Century Steering Group adopted a broad, iterative and collaborative approach in the development of these tools to help ensure they would be as useful as possible to both HCPs and PwMS. These tools have been developed through shared patient-HCP expertise and are based on existing tools in other therapy areas as well as a review of the existing literature and data from MS in the 21st Century Steering Group surveys. The next steps will focus on the validation of these tools through testing them in real-world environments and clinical trials.

Funding: Merck KGaA, Darmstadt, Germany.

Keywords: Communication tools; Shared decision-making; MS care; Neurology

\section{INTRODUCTION}

There has been significant success in the management of multiple sclerosis (MS) over the last 25 years [1]. Yet, despite these advances, patient outcomes in MS remain suboptimal. Reasons for this include variations in the standard of care as well as in patient satisfaction, engagement and adherence [2-5].

Patient adherence is an important factor in MS management [4-6], but can be compromised by

J. Nouvet-Gire

Member of the MS in the 21st Century Steering Group, Paris, France

M. Pontaga

Member of the MS in the 21st Century Steering

Group, Riga, Latvia

P. Rieckmann

Medical Park, Loipl, Bischofswiesen, Germany

S. Schippling

Universitätsspital Zürich, Zurich, Switzerland

N. Alexandri

Global Medical Affairs, Neurology and

Immunology, Merck KGaA, Darmstadt, Germany poor satisfaction with therapy, perceived lack of efficacy, and the occurrence of side effects and tolerability issues $[7,8]$. Good patient-healthcare professional (HCP) communication plays a key role in improving treatment satisfaction and treatment adherence $[7,9,10]$. HCPs have a responsibility to encourage good communication and to provide education, thereby enhancing adherence and addressing low expectations in the management of MS [11-13].

Despite the known benefits of good patient-HCP communication, there are still significant communication barriers between both parties $[3,10]$. The HCP and patient can have different perceptions of the patient's care priorities $[3,9,14]$. Some patients report unmet needs regarding the amount and quality of information they receive from their HCPs during consultations [15]. HCPs also often misjudge patient discomfort regarding discussion of topics such as tremors and walking abilities, as well as sensitive topics that might be considered private, such as bladder control or sexual difficulties [9, 14]. Worryingly, nearly a fifth of patients report feeling uncomfortable about discussing their symptoms with their HCP, specifically neurologists [9]. Some patients felt that their HCP often adopted a "one-size-fits-all" approach, whereas they would prefer a more personalized discussion about their care [3]. For example, some patients with MS (PwMS) felt important personal aspects such as their changing practical needs due to disease progression, as well as their social care and employment issues, were not fully addressed by their HCP during consultations [3].

\section{J. Shanahan}

Member of the MS in the 21st Century Steering Group, Ascot, UK

\author{
H. Thompson \\ Craigavon Hospital, Portadown, UK \\ P. Van Galen \\ Member of the MS in the 21st Century Steering \\ Group, Brussels, Belgium \\ P. Vermersch \\ University of Lille, Lille, France \\ D. Yeandle \\ Member of the MS in the 21st Century Steering \\ Group, Southampton, UK
}


Shared decision-making has been described to be at the heart of patient-centered care [15] and is increasingly recognized as best practice $[9,16]$. Although it is not suited to all patients, this model, which involves patients making informed decisions regarding their care in partnership with their HCP, has been shown to improve overall patient satisfaction and treatment adherence in MS $[9,15,16]$. Increased shared decision-making, including better patient education may improve disease management [15-17].

Shared decision-making requires good communication between the patient and the HCP $[9,16]$. HCPs should adopt a collaborative approach when working with patients, listening to their needs and informing them about the available treatment options [18]. However, in practice, many PwMS often report a lack of objective information and of difficulties making an informed choice [10]. Moreover, surveys of PwMS have found that many patients feel that they have little input into their treatment decisions $[9,12]$. Short consultation times may be one factor contributing to poor patient-HCP communication [19]; many PwMS may feel that they do not get enough contact time with their neurologist $[12,19]$. Some patients have also reported a perceived reluctance of HCPs to prescribe certain medications. HCPs, conversely, cited an inability to prescribe certain medications due to cost restrictions [3]. Disconnects in communication such as these need to be addressed if patient outcomes in MS are to be optimized.

Issues around patient-HCP communication are of particular importance to members of the "MS in the 21st Century" initiative. MS in the 21st Century is led by a Steering Group of 15 MS specialists and 12 patient advocates from 15 countries. Members of this unique initiative collaborate to identify and overcome gaps in patient-HCP communication, and have published eight key actions to help bridge communication gaps within MS treatment and improve the standard of patient-centered care [3]. The Steering Group has a strong commitment to equality of input and mutual respect among members and explicitly adopts a collaborative and inclusive stance in their work [20].

In considering ways to further improve patient-HCP communication, MS in the 21st
Century has created two communication tools: "myMS Priorities" (see supplementary materials) and "myMS Commitments" (see supplementary materials). These tools and the process of their development are described below.

\section{METHODOLOGY}

The development process of the communication tools introduced in this paper took place over a series of HCP-patient joint and separate workshops as part of the activities at the Steering Group's regular planning meetings. These workshops first identified areas of disagreement in the perceptions of patient and HCP priorities through group discussions and survey data. Following the identification of these gaps in communication, the workshops developed potential solutions to help align patient-HCP perceptions and priorities coming up with the concept of the "myMS priorities" pre-consultation checklist and the "myMS commitments" disease management contract. As the last step, the content and format of these communication tools were presented by members of the Steering Group to audiences at international congresses for feedback and validation. In total, 5 workshops were held between March 2016 and July 2017 (Table 1).

\section{Summary of Workshops}

\section{Compliance with Ethics Guidelines}

This publication does not contain any clinical studies with human participants or animals performed by any of the authors. All survey responses were undertaken on a voluntary basis with acceptance of terms outlining the use of the data. All responses were received and analyzed in an aggregated and anonymous format.

\section{RESULTS}

\section{Workshop 1}

The groups identified many similar themes during the separate HCP and PwMS workshops; however, there were key differences in how the 
Table 1 Stages of the MS in the 21st Century communication tool development process

Workshop details
Workshop 1: 22-23 March, 2016, Frankfurt,
Germany. Parallel HCP and PwMS workshops
followed by joint-discussion workshop

Workshop 2: 13 July, 2016, Amsterdam, the Netherlands. PwMS only workshop chaired by HCP member of Steering Group

Workshop 3: 14 September, 2016, London, UK. Joint PwMS--HCP workshop

Workshop 4: 8-9 February, 2017, Barcelona, Spain. Parallel HCP and PwMS workshops followed by joint-discussion workshop

\section{Attendees Objectives}

11 HCPs To review answers to the following three questions:

11 PwMS What are the greatest areas of unmet need in MS care?

What are the most important recent successes in MS care?

What defines or contributes to the concept of treatment burden in MS care?

HCP-patient unmet needs survey (see supplementary materials): After the workshop, MS in the 21st Century developed a survey to further explore differences in the HCP and patient responses. The survey consisted of 10 questions and was run at a series of internal neurology congresses and patient meetings throughout 2016-2018. Respondents typically were highly educated pwMS and neurologists. (Appendix 3)

12 PwMS To further discuss and explore the PwMS perspective on the outputs of the Frankfurt workshops and how differences could be addressed

To develop potential solutions to areas of unmet need for PwMS

To consider how these solutions might also benefit HCPs

10 HCPs

For the HCP members of the Steering Group to input

10 PwMS on the recommendations from the Amsterdam workshop and how HCP perspectives could be addressed

For the joint Steering Group to align on the goals of the proposed communication tools

For the joint Steering Group to begin developing the outline of the tools

7 HCPs

To consider whether the content of the

8 PwMS communication tools could be made more patientfriendly

To consider how the tools would be used by PwMS and HCPs in a real-world setting and to decide on a format to support this use 
Table 1 continued

\begin{tabular}{lll}
\hline Workshop details & Attendees & Objectives \\
\hline $\begin{array}{l}\text { Workshop 5: 5 July, 2017, Windsor, UK. Joint } \\
\text { PwMS-HCP workshop }\end{array}$ & $\begin{array}{l}8 \text { HCPs } \\
7 \text { PwMS }\end{array}$ & $\begin{array}{c}\text { To finalize the content and format of the } \\
\text { communication tools } \\
\text { To develop a joint educational workshop concept for } \\
\text { the presentation of the tools at international } \\
\text { congresses }\end{array}$ \\
\hline
\end{tabular}

Table 2 Comparison of patient and HCP Steering Group perspectives on contemporary issues in MS care

\begin{tabular}{|c|c|c|}
\hline Discussion topic & Patients & HCPs \\
\hline Greatest area of unmet need & $\begin{array}{l}\text { Monitoring of "invisible” symptoms and } \\
\text { mental wellbeing } \\
\text { Access to HCPs } \\
\text { Improve HCP education } \\
\text { Holistic approach to treatment } \\
\text { Personalized care and treatment options } \\
\text { Appropriate patient education/information } \\
\text { Improved public awareness of MS }\end{array}$ & $\begin{array}{l}\text { Symptom-free disease and } \\
\text { ultimately a cure } \\
\text { Continuity and quality of } \\
\text { care } \\
\text { Reimbursement and } \\
\text { accessibility of treatment } \\
\text { Neuroprotective and } \\
\text { personalized treatments } \\
\text { Better treatment for } \\
\text { progressive MS } \\
\text { Patient engagement and } \\
\text { advocacy }\end{array}$ \\
\hline Most important recent successes in MS & $\begin{array}{l}\text { Increased patient support from healthcare } \\
\text { team } \\
\text { Treatment options and diversity of treatment } \\
\text { More focus on quality of life } \\
\text { Globalized online community } \\
\text { Increased focus on progressive MS } \\
\text { Hope for MS patients from treatment, } \\
\text { support, research etc. }\end{array}$ & $\begin{array}{l}\text { Increased treatment options } \\
\text { Improved multidisciplinary } \\
\text { care } \\
\text { Better quality interventions } \\
\text { Enhanced collaboration } \\
\text { between stakeholders } \\
\text { Advances in research }\end{array}$ \\
\hline $\begin{array}{l}\text { What defines or contributes to the concept } \\
\text { of treatment burden? }\end{array}$ & $\begin{array}{l}\text { Risk-benefit balance of treatment } \\
\text { Treatment access } \\
\text { Lack of time with the HCP } \\
\text { Irregular review and monitoring } \\
\text { Geographical differences contribute to } \\
\text { inequality in treatment options } \\
\text { Compliance and adherence }\end{array}$ & $\begin{array}{l}\text { Pharmacovigilance } \\
\text { Side effects } \\
\text { Cost } \\
\text { Inadequate support } \\
\text { Risk-benefit balance of } \\
\text { treatment } \\
\text { Uncertain future }\end{array}$ \\
\hline
\end{tabular}




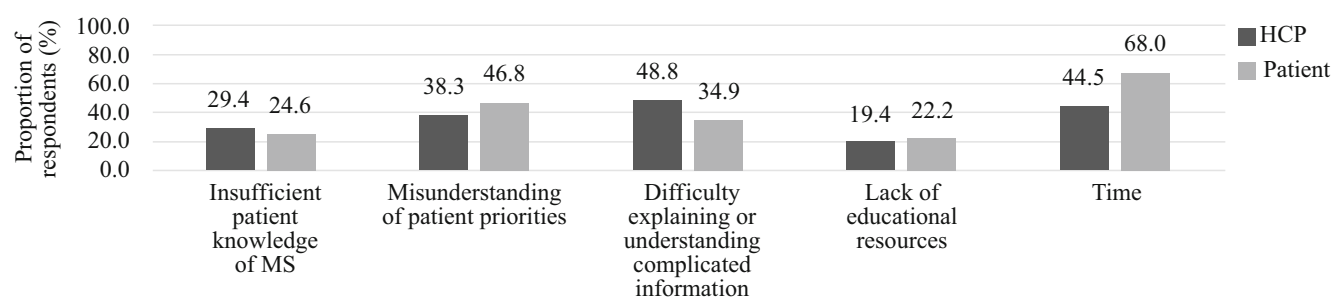

Fig. 1 Factors identified as the biggest barriers to effective communication between HCPs and PwMS (multiple answers permitted)

two groups prioritized the areas of unmet need in MS care (Table 2). Of particular interest were the key priorities "monitoring of invisible symptoms and mental wellbeing" and "improving HCP education" which were identified by the PwMS but not by the HCP group.

\section{Survey}

In total, the "unmet needs" survey (Fig. 1) collected responses from 296 HCPs and 143 PwMS. Of particular interest were the responses to the question "What are the biggest barriers to effective communication between HCPs and PwMS?" The majority of PwMS (68\%) and a large proportion of HCPs (44.5\%) noted "lack of time in appointments" as being the biggest barrier to effective communication.

All survey responses were undertaken on a voluntary basis with acceptance of terms outlining the use of the data. All responses were received and analyzed in an aggregated and anonymous format.

\section{Workshop 2}

It was agreed during this workshop that a "onesize-fits-all" solution to any of unmet needs identified (Table 2) would not be possible based on the individual and unique needs of PwMS. The members therefore decided that the key objective of any MS in the 21st Century activity should be to increase the ability of the HCP to provide, and PwMS to receive, personalized care. Recognizing that the ability of the HCP to provide personalized care is dependent on understanding the needs of the patient; and that there are multiple disconnects in the perceptions of HCPs and PwMS (as highlighted by their previous work), the Steering Group members brainstormed a communication tool that could align PwMS and HCP perspectives.

They proposed the concept of having a "checklist" that would enable PwMS to record their priorities and concerns and then bring this document along to their appointment. The group envisaged that this checklist would also allow PwMS to track and record their symptoms, capture their disease history, and stimulate discussions to cover the symptoms that affect them most, including invisible symptoms that might otherwise be ignored. In addition, they discussed the importance of balancing communication between the patient and HCP in appointments, stressing that the checklist should also allow HCPs to identify their priorities for care.

The group acknowledged that the value of this communication tool was heavily dependent on the level of trust within the patient-HCP relationship. HCPs need to trust that their patients will be honest and open when using the tool and, in turn, PwMS need to trust that their HCP will listen to their perspective and tailor their care accordingly. The group therefore devised the concept of a disease management "contract" between PwMS and the HCP outlining a mutual understanding of each other's responsibilities within the relationship and providing a foundation for balanced conversations and realistic treatment expectations.

\section{Workshop 3}

It was decided that, to maximize the potential of the checklist, it is essential that PwMS share the completed version with their HCP in 
advance of the consultation. This ensures that the HCP has sufficient time to consider their patient's priorities and plan accordingly. For example, sending the checklist beforehand, on the morning of the consultation, could enable both parties to make the best use of the limited time available during the consultation and to ensure that all priorities are sufficiently addressed.

It was also decided that it was vital for the disease management contract to be framed as an agreement between equal partners in MS management, and for it not to get interpreted as a binding adherence contract. By the end of the workshop, the joint Steering Group members had agreed upon and defined the objectives of each of the communication tools (Table 3) and begun developing the content of both tools.

\section{Workshop 4}

The Steering Group decided that, in order to best achieve its objectives, the checklist should not be a "tick box" of provided options but, instead, have an open structure allowing both parties to record their priorities in their own words. The Steering Group named this preconsultation checklist tool "myMS priorities" in order to accurately reflect this content and goal.

In view of the other objectives of the "myMS priorities" tool, the Steering Group added specific sections covering changes to symptoms, medication and lifestyle. A section allowing PwMS to record changes to their symptoms since their last appointment was also included with the aim of providing PwMS a way for them to raise potentially sensitive topics such as sexual function and relationship questions as well as ensuring that invisible symptoms are sufficiently recognized and addressed by their HCP (Table 4).

To support shared decision-making, a section that allows PwMS to share information about their current treatment experience including non-prescription therapies and other prescription medications was added. Also, to support PwMS empowerment and self-management, a section was included allowing PwMS to record changes to their lifestyle and any feelings
Table 3 Objectives of the two communication tools as defined by the Steering Group during Workshop 3

\begin{tabular}{|c|c|}
\hline Pre-consultation checklist & $\begin{array}{l}\text { Disease management } \\
\text { contract }\end{array}$ \\
\hline $\begin{array}{l}\text { To ensure that the patient's } \\
\text { priorities and concerns } \\
\text { are openly acknowledged } \\
\text { by their doctor }\end{array}$ & $\begin{array}{l}\text { To help MS patients and } \\
\text { their doctors to share } \\
\text { information and disease } \\
\text { management } \\
\text { responsibilities }\end{array}$ \\
\hline $\begin{array}{l}\text { To provide an opportunity } \\
\text { for HCPs to also identify } \\
\text { their priorities for the } \\
\text { consultation }\end{array}$ & $\begin{array}{l}\text { To improve self- } \\
\text { management and } \\
\text { treatment adherence of } \\
\text { patients }\end{array}$ \\
\hline $\begin{array}{l}\text { To ensure that all } \\
\text { symptoms, concerns and } \\
\text { feelings (positive and } \\
\text { negative) are recorded } \\
\text { and provided to an HCP } \\
\text { ahead of appointments }\end{array}$ & $\begin{array}{l}\text { To facilitate greater trust in } \\
\text { the patient-HCP } \\
\text { relationship }\end{array}$ \\
\hline $\begin{array}{l}\text { To share information that } \\
\text { may affect management } \\
\text { decisions }\end{array}$ & $\begin{array}{l}\text { To encourage confident, } \\
\text { open interaction between } \\
\text { both parties }\end{array}$ \\
\hline $\begin{array}{l}\text { To make the best use of the } \\
\text { time available during a } \\
\text { consultation }\end{array}$ & $\begin{array}{l}\text { To encourage greater levels } \\
\text { of openness between } \\
\text { patients and their support } \\
\text { network }\end{array}$ \\
\hline
\end{tabular}

regarding how this affected their health. Finally, recognizing the importance of PwMS support networks, a section was added to allow partners, family members, friends, or caregivers to note any questions they might have for the HCP.

In developing the second tool, the Steering Group members re-iterated that this tool was needed to underpin the open and honest communication between HCPs and PwMS that was considered essential for the effective use of the pre-consultation checklist-based, "myMS priorities" tool. They again highlighted the importance of emphasizing that the tool is not intended to be a contract or mandatory document, but rather an opportunity for the patient to participate in improving their own care. 
Table 4 Topics included in the symptoms tracker section of the my MS priorities tool

Moving and walking
Stiffness and spasms
Balance and dizziness
Pain and sensation
Vision
Speech
Hearing
Bladder and bowel
Fatigue and sleep
Moods and emotions
Concentration and memory
Relationships and sexual function
Infections
Other concerns

Considering these aspects, as well as the overall objectives of the tool, the group decided to call this disease management agreement-based tool "myMS commitments".

The PwMS and HCP Steering Group members discussed the responsibilities that they would expect from each other in order to maximize the efficacy of the tool in MS care. These responsibilities were then included in the statements of "commitment" for both the PwMS and the healthcare team and grouped into common themes. The four themes included in the final version of the "myMS commitments" tool are "understanding and learning about MS", "how to get the best from appointments", "MS treatment and management", and "how to get the best out of life".

\section{Workshop 5}

At the final workshop, the Steering Group considered how the tools should be presented and used. It was felt important that users should have the choice between both physical and digital copies of the tools as these have different but complementary benefits. Digital versions of the tools make it easy for the PwMS to refer to the tool throughout the year. They also simplify the sharing process between the PwMS and HCP and remove the risk of the tool being lost or not brought to the appointment. However, it was felt that many PwMS may prefer to use paper versions of the tools for reasons such as ease of use during appointments and in order to involve a family member, friend, or carer in the process of using the tool, both of which might be particularly important for patients with cognitive impairment.

In order to gather feedback on the tools, including any possible limitations, the Steering Group developed a workshop format for use at international neurology congresses and PwMS meetings. The workshop series titled "Two monologues do not make a dialogue" used roleplay videos developed by the Steering Group to highlight common issues encountered by both PwMS and HCPs during appointments and how the "myMS priorities" and "myMS commitments" tools could enhance these interactions. These workshops were run at three international congresses and one patient conference. ${ }^{1}$

The feedback from this workshop series came from both HCPs and PwMS. For HCPs, possible limitations identified included time constraints which could prevent pre-appointment preparation and the possible loss of tool copies, especially when in transit to the HCP. Possible limitations for PwMS included their opinion that the tool is unnecessary, priorities changing before appointments, and, importantly, any cognitive or physical difficulties which could impair their ability to complete the forms.

\footnotetext{
1 The "Two monologues do not make a dialogue" workshops were conducted at international congresses ECTRIMS 2017, ECF 2017, CMSC 2018 and a Merck Patient Ambassador Summit 2018.
} 


\section{MYMS PRIORITIES (PRE- CONSULTATION CHECKLIST- BASED TOOL)}

The priorities tool enables PwMS to record their personal priorities for each appointment in a dedicated section which can be shared with the doctor, MS nurse or other members of the healthcare team in advance ("tear off" section can be sent ahead of appointment).

\section{Benefits for the Patient}

The tool allows PwMS to structure their questions and concerns, and to come to each appointment fully prepared. It also prompts recollection of changes since the last appointment and offers the opportunity to raise difficult or sensitive issues (e.g., relationships, sexual health, employment) which may not be as high on the HCP's list of priorities. If patients feel they are being listened to and that their doctor and MS nurse are focusing on their needs, they will feel greater satisfaction regarding their care.

\section{Benefits for the HCP}

Receipt of patient priorities ahead of appointments allows the HCP and healthcare team to gain important insight into the issues that are of the highest priority to the PwMS, ensures effective use of consultation time and offers the opportunity to prepare and plan referrals ahead of time. Healthcare team priorities for each appointment can also be shared for the PwMS to consider.

\section{mYMS COMMITMENTS (DISEASE MANAGEMENT AGREEMENT-BASED TOOL)}

The commitments tool is an "agreement document" that outlines the ways in which PwMS and HCPs can each take responsibility in the management of MS. It offers the PwMS and their HCP the chance to agree and commit, in a non-binding way, to their respective responsibilities.

\section{Benefits for the Patient}

Identifying the aspects of care where PwMS can have agency over their management can increase patient feelings of empowerment. This in turn supports a more open and honest relationship with the healthcare team and instils and builds confidence in patients to discuss their disease management.

\section{Benefits for the HCP}

The tool also outlines a realistic idea of what PwMS can expect from their healthcare team, and what the healthcare team can in turn expect from them, increasing trust and encouraging more holistic and personalized care. Increased patient engagement leads to better adherence to management and treatment, while shared responsibility for patient education reduces the risks of patients turning to unverified sources of information online. 


\section{DISCUSSION}

Chronic conditions such as MS for which patients require lifelong treatment, and for which multiple treatment options of similar efficacy exist, may strongly benefit from a good patient-HCP relationship which facilitates shared decision-making $[9,15,16]$. A number of communication tools exist for chronic conditions, including MS, and have been associated with improved outcomes such as increased patient satisfaction and knowledge [21-23]. In order to improve patient-HCP communication, MS in the 21st Century has developed two communication tools, the pre-consultation checklist-based, "myMS priorities" and the disease management agreement-based, "myMS commitments".

The MS in the 21st Century Steering Group adopted a broad, iterative and collaborative approach in the development of these tools to help ensure that they would be as useful as possible to both HCPs and PwMS. These tools have been developed through shared patient-HCP expertise and are based on existing tools in other therapy areas, as well as a review of the existing literature and data from MS in the 21st Century Steering Group surveys. Both the literature review and survey data identified lack of HCP time in appointments [12] and misalignment of patient and HCP priorities in MS care as prominent gaps in patient-HCP communication [3, 9].

A series of meetings were held with clear objectives to outline the development and content finalization of the tools. The workshops and sessions were also set up to encourage as much HCP-patient interaction and collaboration as possible. Further, the inclusion of multinational participants aimed to make the tools applicable to the largest population possible. The fact that the tools are not linked to any specific MS treatment means that they can be used by all patients, regardless of their disease status. The tools are currently available in six languages (English, French, German, Spanish, Italian, Romanian) to increase accessibility. The final step in the development of these tools focused on gaining feedback from a wider audience through workshops, specifically at three international congresses.

Existing communication tools which the MS in the 21st Century Steering Group considered when creating "myMS priorities" and "myMS commitments" included patient-physician contracts, symptom diaries and checklists. The patient-HCP contract has been used in fields such as diabetes, hypertension, weight control and opioid addiction management [23-26]. Contracts are agreements between the patient and HCP detailing the responsibilities of both parties toward the patient's care. Studies have shown contracts to increase patient adherence in various patient populations $[23,24]$. However, many different types of contracts exist and, while there is documented efficacy for some types of contract, other types have shown limited efficacy at best [27].

The patient-provider agreement is an example of a contract used in opioid addiction treatment for which studies have demonstrated only weak efficacy. These contracts often include a section describing the "consequences" (to the patient) of non-compliance with the agreement [28]. When reviewing such contracts, Bachman and Ho [29] identified that "if patients distrust their HCP, or feel distrusted by them, this may destabilize the therapeutic relationship and compromise care". Colleen [30] also echoed this view, citing that opioid contracts lacked efficacy and diminished patients trust while also mentioning "patient's trust improves adherence to treatment".

The diabetes responsibility contract is another type of contract used in clinical practice. This type of agreement focuses on patient empowerment and may increase treatment adherence [31, 32]. In contrast to "consequences" for non-compliance of the patient to opioid agreements, many diabetes responsibility contracts provide positive reinforcement for patients when they fulfil their agreed commitments [32].

When creating the "myMS Commitments" tool, MS in the 21st Century Steering Group members were acutely aware that contracts, while proven to be beneficial, could do more harm than good if not created properly. This is due to the inherent power imbalance that exists 
in patient-HCP relationships [25]. In attempting to address this imbalance, the group based this contract on shared decision-making and promoting patient empowerment, factors known to increase patient satisfaction and treatment adherence $[9,33]$.

When creating the "myMS Priorities" tool, the MS in the 21st Century Steering Group wanted to combine selected benefits of symptom diaries and checklists into a new, single tool. Symptom diaries can improve treatment adherence, and both patients and HCPs have shown their willingness to use them. These diaries are traditionally used to help patients record their symptoms-and in some cases their effect on the patient-accurately. Without a diary, the patient would need to rely purely on their memory to recall symptoms at their next consultation with their HCP, which could be imprecise especially when there is a long period of time between consultations [34]. This is particularly relevant in MS where as many as $40-65 \%$ of patients may have some form of cognitive impairment [35]. The patient can complete "myMS Priorities" at home with help from their family or caregiver, which again may be particularly relevant for PwMS who have cognitive impairment.

Unlike existing symptom diaries in MS such as the MS symptom and impact diary [36], which are tools which record symptoms as a measure of the impact of MS on the patient, the "myMS Priorities" tool aims to help patients and HCPs start conversations about potentially embarrassing or invisible symptoms. Recording their sensitive symptoms in "myMS Priorities" allows patients to raise such symptoms with their HCP via the tool rather than relying on the HCP to ask the patient about them.

Checklists can help guide the patient and HCP through a consultation and ensure that all relevant topics and needed actions are covered $[37,38]$. For example, a "What to ask your doctor" patient appointment guide developed by the NHS lists some suggested questions for consultations [39]. The MS in the 21st Century Steering Group saw the value in the patient listing their priorities, much as they would appear in checklists, to guide and cover topics quickly during a time-limited patient-HCP consultation. They also noted that, unlike checklists, patient diary responses were openended as opposed to a tick in the box, thereby allowing the patient to express their priorities in more detail and guide discussions. Consequently, the "myMS Priorities" tool allows patients to list priorities much in the style of a checklist but also describe their priorities in a similar way to describing symptoms in a symptom diary. The availability of both tools in paper or electronic versions offers patients and physicians the option to choose their preferred format based on factors such as convenience and ease of completion.

As with many communication tools, the limitations of "myMS Commitments" and "myMS Priorities" relate to commitment to their use by patients and HCPs. Possible limitations of the tools, including that gathered from feedback in international congresses, are that the HCP may not always have the time in clinical practice to optimally use the tools, and that patients may sometimes not have the will or ability to use them. Another limitation is that, while a diverse range of participants were used in the development of the tool, additional responses from patient caregivers and the families of PwMS could have been beneficial. Finally, patients who are more engaged with their MS care, such as those who research and probatively manage their condition, may be more likely and open to use these tools than patients who take a less active approach to their management. In addition, the data gathered to support the development of these tools were likely predominately from more highly engaged and educated PwMS. While this could lead to a bias in the survey responses, the group would hypothesize that the communication gap between HCPs and PwMS in a standard clinical setting is therefore in fact far greater than has been identified in the data collected here.

To the authors' knowledge, no communication tools such as "myMS priorities" and "myMS commitments" currently exist for PwMS. While remote and digital tools for PwMS are available, they are not specifically aimed at the doctor-patient relationship in the form of a "contract" or to minimize disparities in treatment perceptions [40]. Nor do such tools have the 
same basis in research for their development as that for "myMS priorities" and "myMS commitments".

\section{CONCLUSIONS}

Development of the pre-consultation checklistbased "myMS priorities" and disease management agreement-based "myMS commitments" tools has followed a thorough and systematic approach. The MS in the 21st Century Steering Group has identified two areas in MS care which are most in need of improvement, and has targeted them with two new communication tools which have evolved through incorporating and combining some features of existing communication tools.

Thus, "myMS priorities" and "myMS commitments" offer an opportunity to engage and empower patients in their MS care through a strengthened patient-HCP relationship. This could therefore meaningfully improve outcomes in MS. The next steps will focus on the validation of these tools through testing them in real-world environments. These data will be assessed for improvements in communication and shared decision-making and to see if this is reflected by improved patient and HCP reported outcomes.

\section{ACKNOWLEDGEMENTS}

We thank the MS in the 21st Century steering group members for their participation in the development of these tools, and the respondents of the survey for their valuable contribution to the dataset.

Funding. The MS in the 21st Century initiative is financially supported by Merck KGaA, Darmstadt, Germany. The journal's Rapid Service Fee and Open Access Fees were also funded by Merck KGaA, Darmstadt, Germany. All authors had full access to all of the data in this study and take complete responsibility for the integrity of the data and accuracy of the data analysis.
Editorial Assistance. Administrative support and editorial input was provided by Cello Health Communications. Medical writing assistance was provided by Cello Health Communications (Owen Webb, Helen Hammond, and Rudy Sarmah). Administrative support, medical writing assistance, and journal submission fees were funded by Merck KGaA, Darmstadt, Germany.

Authorship. All named authors had full access to all of the content within this manuscript and take complete responsibility for the integrity and accuracy of the content. All named authors meet the International Committee of Medical Journal Editors (ICMJE) criteria for authorship for this article, take responsibility for the integrity of the work as a whole, and have given their approval for this version to be published.

List of Members of MS in the 21st Century. The members of MS in the 21st Century are as follows: Birgit Bauer, Diego Centonze, Maria Paz Giambastiani, Gavin Giovannoni, Jürg Kesselring, Dawn Langdon, Sarah A Morrow, Jocelyne Nouvet-Gire, Celia Oreja-Guevara, Maija Pontaga, Stanca Potra, Peter Rieckmann, Sven Schippling, Jane Shanahan, Heidi Thompson, Pieter van Galen, Patrick Vermersch, and David Yeandle.

Disclosures. All Steering Group members receive honoraria from Merck $\mathrm{KGaA}$ as part of their work on MS in the 21st Century.

Peter Rieckmann has received honoraria for lectures from Almirall, Apple Healthcare, Baxter, Bayer, Biogen Idec, Boehringer-Ingelheim, Cerner, Daiichi Sankyo, Genpharm, Genzyme, Medtronic, Merck, Novartis, Pfizer, Roche, Sanofi-Aventis, Siemens AG, and Teva. He has received research grants from Bayer, EMD Serono, Novartis, Teva, the MS Society of Canada, Canadian Institutes of Health Research, Hertie Foundation, Oberfranken-Stiftung, and German Neurology Foundation. He is on an advisory board or steering committee for AbbVie, Bayer, Biogen Idec, Novartis, Merck, Teva, the German Multiple Sclerosis Society, and Canada Drug Review. 
Gavin Giovannoni is a steering committee member for AbbVie (daclizumab trials) and Biogen Idec (BG12 and daclizumab trials), and has received honoraria for speaking from Canbex Therapeutics. He is a clinical advisor regarding the development of VSN16. He has received consultancy fees for advisory board meetings for GW Pharmaceuticals, and for speaking at the launch of Sativex in Norway.

Dawn Langdon has participated in speakers bureaus for Bayer, Merck, Almirall, Excemed, Teva, Roche, Novartis, Biogen, and Sanofi; has received consultancy honoraria from Novartis, Bayer, Merck, Biogen, Teva, and Sanofi; and has received research grants from Bayer, Merck, Novartis, and Biogen, all paid to her institution.

Patrick Vermersch receives honoraria and consulting fees from Biogen, Sanofi Genzyme, Bayer, Novartis, Teva, Merck, Celgene and Almirall. Research support from Biogen, Sanofi Genzyme, Bayer and Merck.

Sven Schippling receives consulting and speaker fees and travel grants from Biogen Idec, Bayer, Merck, Sanofi Genzyme/Sanofi Aventis, Novartis, Teva, and research grants from Bayer, Biogen Idec, Merck Serono, Sanofi Genzyme/ Sanofi Aventis, Novartis.

Jürg Kesselring receives honoraria from Merck. Diego Centonze is an advisory board member of Almirall, Bayer Schering, Biogen, GW Pharmaceuticals, Merck, Novartis, Roche, SanofiGenzyme, Teva and has received honoraria for speaking or consultation fees from Almirall, Bayer Schering, Biogen, GW Pharmaceuticals, Merck, Novartis, Roche, Sanofi-Genzyme, Teva. $\mathrm{He}$ is also the principal investigator in clinical trials for Bayer Schering, Biogen, Merck, Mitsubishi, Novartis, Roche, Sanofi-Genzyme, Teva. His preclinical and clinical research was supported by grants from Bayer Schering, Biogen Idec, Celgene, Merck, Novartis, Roche, Sanofi-Genzyme, Teva.

Sarah A Morrow has received honoraria for speaking, consulting, and advisory board participation from Biogen Idec, EMD, Genzyme, Novartis, and Roche. She has acted as site principal investigator for clinical trials for Novartis, Genzyme and Roche. She has received investigator initiated trial funding from Genzyme.
Celia Oreja-Guevara has received honoraria from Biogen Idec, Novartis, Sanofi Genzyme, Almirall, Merck.

Heidi Thompson has received honoraria for advisory board participation and travel grants from Merck and Biogen.

Nektaria Alexandri is a Merck KGaA employee. Jane Shanahan, Pieter Van Galen and David Yeandle have nothing to disclose.

Compliance with Ethics Guidelines. This publication does not contain any clinical studies with human participants or animals performed by any of the authors. All survey responses were undertaken on a voluntary basis with acceptance of terms outlining the use of the data. All responses were received and analyzed in an aggregated and anonymous format.

Data Availability. The datasets during and/ or analyzed during the current study are available from the corresponding author on reasonable request.

Open Access. This article is distributed under the terms of the Creative Commons Attribution-NonCommercial 4.0 International License (http://creativecommons.org/licenses/ by-nc/4.0/), which permits any noncommercial use, distribution, and reproduction in any medium, provided you give appropriate credit to the original author(s) and the source, provide a link to the Creative Commons license, and indicate if changes were made.

\section{REFERENCES}

1. Cerqueira JJ, Compston DAS, Geraldes R, et al. Time matters in multiple sclerosis: can early treatment and long-term follow-up ensure everyone benefits from the latest advances in multiple sclerosis? J Neurol Neurosurg Psychiatry. 2018;89(8):844-50.

2. Rieckmann P, Boyko A, Centonze D, et al. Future MS care: a consensus statement of the MS in the 21st Century Steering Group. J Neurol. 2013;260(2):462-9.

3. Rieckmann P, Centonze D, Elovaara I, et al. Unmet needs, burden of treatment, and patient engagement in multiple sclerosis: a combined perspective 
from the MS in the 21st Century Steering Group. Mult Scler Relat Disord. 2018;19:153-60.

4. Rieckmann P, Boyko A, Centonze D, et al. Achieving patient engagement in multiple sclerosis: a perspective from the multiple sclerosis in the 21st Century Steering Group. Mult Scler Relat Disord. 2015;4(3):202-18.

5. Lugaresi A, Ziemssen T, Oreja-Guevara C, Thomas D, Verdun E. Improving patient-physician dialog: commentary on the results of the MS choices survey. Patient Prefer Adher. 2012;6:143-52.

6. Katsarava Z, Ehlken B, Limmroth V, et al. Adherence and cost in multiple sclerosis patients treated with IM IFN beta-1a: impact of the CARE patient management program. BMC Neurol. 2015;15:170.

7. Devonshire V, Lapierre $\mathrm{Y}$, Macdonell $\mathrm{R}$, et al. The global adherence project (GAP): a multicenter observational study on adherence to disease-modifying therapies in patients with relapsing-remitting multiple sclerosis. Eur J Neurol. 2011;18(1):69-77.

8. Morillo Verdugo R, Ramírez Herráiz E, FernándezDel Olmo R, et al. Adherence to disease-modifying treatments in patients with multiple sclerosis in Spain. Patient Prefer Adher. 2019;13:261-72.

9. Tintoré M, Alexander M, Costello K, et al. The state of multiple sclerosis: current insight into the patient/health care provider relationship, treatment challenges, and satisfaction. Patient Prefer Adher. 2017;11:33-45.

10. Zettl UK, Bauer-Steinhusen U, Glaser T, Hechenbichler K, Hecker M, Study Group. Comparative evaluation of patients' and physicians' satisfaction with interferon beta-1b therapy. BMC Neurol. 2016;16(1):181.

11. Treadaway K, Cutter G, Salter A, et al. Factors that influence adherence with disease-modifying therapy in MS. J Neurol. 2009;256(4):568-76.

12. de Seze J, Borgel F, Brudon F. Patient perceptions of multiple sclerosis and its treatment. Patient Prefer Adher. 2012;6:263-73.

13. Reen GK, Silber E, Langdon DW. Multiple sclerosis patients' understanding and preferences for risks and benefits of disease-modifying drugs: a systematic review. J Neurol Sci. 2017;375:107-22.

14. Heesen C, Haase R, Melzig S, et al. Perceptions on the value of bodily functions in multiple sclerosis. Acta Neurol Scand. 2018;137(3):356-62.

15. Colligan E, Metzler A, Tiryaki E. Shared decisionmaking in multiple sclerosis. Mult Scler. 2017;23(2):185-90.
16. Ben-Zacharia A, Adamson M, Boyd A, et al. Impact of shared decision making on disease-modifying drug adherence in multiple sclerosis. Int J MS Care. 2018;20(6):287-97.

17. Köpke S, Kasper J, Mühlhauser I, Nübling M, Heesen C. Patient education program to enhance decision autonomy in multiple sclerosis relapse management: a randomized-controlled trial. Mult Scler. 2009;15(1):96-104.

18. Armstrong MJ, Shulman LM, Vandigo J, Mullins CD. Patient engagement and shared decision-making: what do they look like in neurology practice? Neurol Clin Pract. 2016;6(2):190-7.

19. Yoshioka N, Ishii H, Tajima N, Iwamoto Y, DAWN Japan Group. Differences in physician and patient perceptions about insulin therapy for management of type 2 diabetes: the DAWN Japan study. Curr Med Res Opin. 2014;30(2):177-83.

20. Yeandle D, Rieckmann P, Giovannoni G, et al. Patient power revolution in multiple sclerosis: navigating the new frontier. Neurol Ther. 2018;7(2):179-87.

21. Köpke S, Solari A, Khan F, Heesen C, Giordano A. Information provision for people with multiple sclerosis. Cochrane Database Syst Rev. 2018. https:// doi.org/10.1002/14651858.CD008757.pub3.

22. Solari A, Martinelli V, Trojano M, et al. An information aid for newly diagnosed multiple sclerosis patients improves disease knowledge and satisfaction with care. Mult Scler. 2010;16(11):1393-405.

23. Chisholm-Burns MA, Spivey CA, Graff Zivin J, Lee JK, Sredzinski E, Tolley EA. Improving outcomes of renal transplant recipients with behavioral adherence contracts: a randomized controlled trial. Am J Transplant. 2013;13(9):2364-73.

24. Bosch-Capblanch X, Abba K, Prictor M, Garner P. Contracts between patients and healthcare practitioners for improving patients' adherence to treatment, prevention and health promotion activities. Cochrane Database Syst Rev. 2007. https://doi.org/ 10.1002/14651858.CD004808.pub3.

25. Lieber SR, Kim SY, Volk ML. Power and control: contracts and the patient-physician relationship. Int J Clin Pract. 2011;65(12):1214-7.

26. Denmark D. patient-physician partnering to improve chronic disease care. Fam Pract Manag. 2004;11(5):55-6.

27. Starrels JL, Becker WC, Alford DP, Kapoor A, Williams AR, Turner BJ. Systematic review: treatment agreements and urine drug testing to reduce opioid 
misuse in patients with chronic pain. Ann Intern Med. 2010;152(11):712-20.

28. Albrecht JS, Khokhar B, Pradel F, Campbell M, Palmer J, Harris I. Perceptions of patient provider agreements. J Pharm Health Serv Res. 2015;6(3):139-44.

29. Buchman DZ, Ho A. What's trust got to do with it? Revisiting opioid contracts. J Med Ethics. 2014;40(10):673-7.

30. Collen M. Opioid contracts and random drug testing for people with chronic pain-think twice. J Law Med Ethics. 2009;37(4):841-5.

31. Egede LE, Strom JL, Durkalski VL, Mauldin PD, Moran WP. Rationale and design: telephone-delivered behavioral skills interventions for blacks with type 2 diabetes. Trials. 2010;11:35.

32. Carroll AE, DiMeglio LA, Stein S, Marrero DG. Contracting and monitoring relationships for adolescents with type 1 diabetes: a pilot study. Diabetes Technol Ther. 2011;13(5):543-9.

33. Náfrádi L, Nakamoto $\mathrm{K}$, Schulz PJ. Is patient empowerment the key to promote adherence? A systematic review of the relationship between self-efficacy, health locus of control and medication adherence. PLoS ONE. 2017;12(10): e0186458.
34. Baggott C, Gibson F, Coll B, Kletter R, Zeltzer P, Miaskowski C. Initial evaluation of an electronic symptom diary for adolescents with cancer. JMIR Res Protoc. 2012;1(2):e23.

35. Langdon DW. Cognition in multiple sclerosis. Curr Opin Neurol. 2011;24(3):244-9.

36. Greenhalgh J, Ford H, Long AF, Hurst K. The MS symptom and impact diary (MSSID): psychometric evaluation of a new instrument to measure the day to day impact of multiple sclerosis. J Neurol Neurosurg Psychiatry. 2004;75(4):577-82.

37. Hales B, Terblanche M, Fowler R, Sibbald W. Development of medical checklists for improved quality of patient care. Int J Qual Health Care. 2008;20(1):22-30.

38. MacDonald E, editor. Difficult conversations in medicine. Oxford: Oxford University Press; 2004.

39. NHS. NHS Services: what to ask your doctor. https://www.nhs.uk/using-the-nhs/nhs-services/ gps/what-to-ask-your-doctor/ (2019). Accessed 3 April 2019.

40. Marziniak M, Brichetto G, Feys P, Meyding-Lamadé $\mathrm{U}$, Vernon K, Meuth SG. The use of digital and remote communication technologies as a tool for multiple sclerosis management: narrative review. JMIR Rehabil Assist Technol. 2018;5(1):e5. 